\title{
Comparison between Single Shot Micromachining of Silicon with Nanosecond Pulse Shaped IR Fibre Laser and DPSS UV Laser
}

\author{
Kun Li, Martin Sparkes, and William O’Neill
}

\begin{abstract}
High power DPSS UV laser having high repetition rates $(>100 \mathrm{kHz})$ are significant part of the cost of a laser $\mathrm{Si}$ micro-processing system. An alternative inexpensive solution, MOPA based IR fibre lasers, have been used to machine Si with high energy shaped pulses. This investigation evaluates the single pulse machining performance of a pulse shapeable IR $(1062 \mathrm{~nm})$ fibre laser and a DPSS UV (355 $\mathrm{nm})$ laser on Si substrates and directly compares their performance. The machined depth data was measured with a white light interferometer and the finishing quality examined for surface defects with a SEM. Theoretical analysis demonstrated rapid heating effects by taking account of the dynamic optical and thermal properties of $\mathrm{Si}$ for given IR laser pulse shapes. The results show that high quality $\mathrm{Si}$ surface micro-processing can benefit from using the more flexible, more reliable, and pulse shapeable IR fibre laser at high repetition rates which no conventional solid state IR or UV laser could achieve.
\end{abstract}

Index Terms - IR fibre laser, DPSS UV laser, micromachining, silicon, optical, thermal dynamic properties

\section{INTRODUCTION}

$\mathrm{F}$ OR MANY years, Q-switched Diode Pumped Solid State (DPSS) UV (355 nm) laser have been implemented to process $\mathrm{Si}$ for microelectronics, surface engineering and surface texturing [1] [2] [3] and photovoltaic applications [4] [5]. A $355 \mathrm{~nm}$ DPSS laser was used to structure a Si substrate for improved surface hydrophobicity, the structured micro-size pits could then be imprinted onto the sol-gel film for mass production [6]. Besides scribing and edge isolation, photovoltaic cells (black silicon) were textured to increase

This work was supported in part by the Engineering and Physical Sciences Research Council (EPSRC), U.K., under Grant RG 453279, and by the SPI Lasers, Southampton, U.K.

Kun $\mathrm{Li}$ was with the Centre for Industrial Photonics, Institute for Manufacturing, Department of Engineering, University of Cambridge, 17 Charles Babbage Road, Cambridge, CB3 OFS. He is now with the Photonics \& Sensors Group, Electrical Engineering Division, Department of Engineering, University of Cambridge, 9 JJ Thomson Avenue, Cambridge, CB3 0FA, U.K. (e-mail: k1330@cam.ac.uk).

Martin Sparkes and William O'Neill are with the Centre for Industrial Photonics, Institute for Manufacturing, Department of Engineering, University of Cambridge, 17 Charles Babbage Road, Cambridge, CB3 OFS, U.K. (e-mail: mrs46@cam.ac.uk; wo207@cam.ac.uk). solar radiation absorption with lasers of different wavelengths to trap light [7] [8].

There is a continuous push for increased UV power and conversion efficiency to improve manufacturing throughput, unfortunately DPSS UV lasers have reduced average power and pulse peak power with increasing repetition rates. Recently $43.7 \mathrm{~W}$ at $400 \mathrm{kHz}$ has been reported with $\sim 41.6 \%$ conversion efficiency [9]. However, challenges such as complicated optics, stable resonators, pump energy delivery and thermal management are unavoidable during scale-up which result in high system costs. As a result $\mathrm{Si}$ device manufacturers are looking for an alternative laser source capable of equivalent quality.

IR fibre lasers have already demonstrated high quality machining of Si using high peak power pulses [10] [11]. The machined depth and quality were investigated with IR pulses of different pulse lengths and peak powers [12] [13]. The energy coupling was thought to be different from the more common IR laser volumetric heating of $\mathrm{Si}$ with the fast rising, high front peak pulse shape effecting a change in a material's optical and thermal properties [14]. There is a lack of published research directly comparing the single pulse processing of $\mathrm{Si}$ for the two laser types with the aid of surface temperature distribution.

The paper seeks to evaluate the machining performance of IR fibre laser against a DPSS UV laser in terms of single pulse material interaction on Si. The comparison addresses the single pulse machined depth, machining mechanism, energy efficiency and hole quality. The temperature distribution of a Si surface is computed based on the heat conduction model for both the UV and IR laser, results then used to explain the empirical findings. The outcome evaluation will assist the laser selection decision for the photovoltaic and surface engineering applications.

\section{EXPERIMENTS}

The IR $(1062 \mathrm{~nm})$ source was a MOPA based $20 \mathrm{~W}$ pulsed $\mathrm{Yb}$ doped fibre laser, G3 SM-S00044_1, from SPI lasers, Southampton, UK. The laser has 25 pre-set waveforms for optimised peak pulse power at specified pulse lengths, some shown in Fig. 1. The laser beam is delivered to the work piece using a XLR8 x-y scan head from Nutfield Technology Inc., 
Hudson, USA. Scan patterns are software generated (WaveRunner, Nutfield Inc.) which allowed the materials interactions to be investigated whilst allowing full control of all laser parameters. An F-theta scan lens of focal length $125.1 \mathrm{~mm}$ is used, the minimum spot size was calculated to be $25.4 \mu \mathrm{m}$ with a beam input diameter of $8 \mathrm{~mm}$.

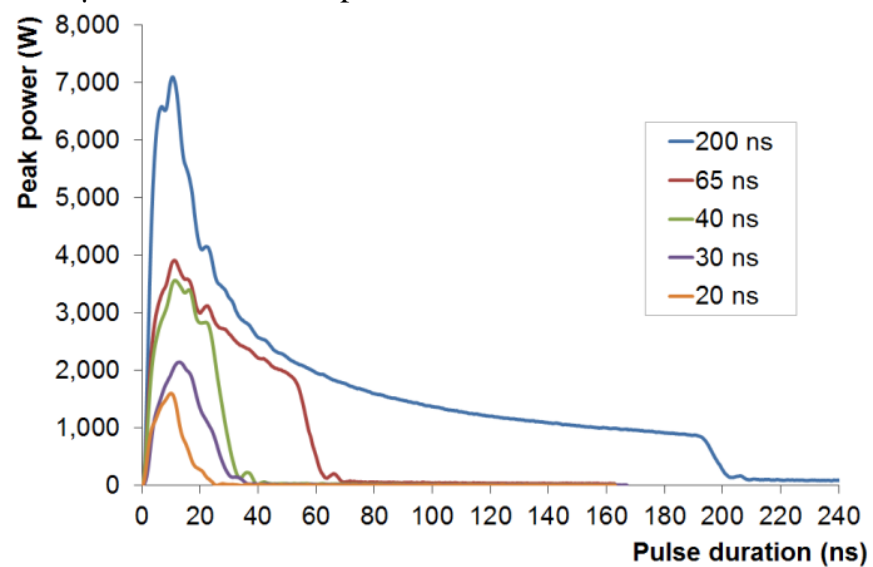

Fig. 1. IR laser waveforms for optimized pulse peak power at specified pulse lengths.

The UV laser (355 nm) used was a Coherent AVIA 355-10 (Santa Clara, CA, USA). The UV laser was integrated with a similar scan head containing a $103 \mathrm{~mm}$ focal lens. The minimum spot size was calculated to be $17 \mu \mathrm{m}$ with the beam input diameter of $3.5 \mathrm{~mm}$.

Both laser system specifications are summarised in Table 1 for comparison.

The pulse shapes of both the IR laser and the UV laser were measured. The tools used included a $\mathrm{Si}$ Biased Detector (DET10A/M, 200-1100 nm, 1 ns Rise Time, THORLABS), a digital oscilloscope (Lecroy WaveRunner $6050 \mathrm{~A}, 500 \mathrm{MHz}$ analogue bandwidth, $5 \mathrm{GS} / \mathrm{s}$ single-shot sample rate). The photodiode was placed a few centimetres from the laser material interaction zone to collect scattered light, the laser being defocused to avoid ablation. During the measurement process the substrate was not melted, which limited variation of the amount of light with temperature.

The measured data was integrated with pulse energy to calculate the peak power, Fig. 1, Fig. 2 and Fig. 3. The $200 \mathrm{~ns}$ IR laser pulse has a shape with fast rise time $(<7.5 \mathrm{~ns}$ for a $10-90 \%$ rise in signal) and an energetic long tail ( 180 ns). The UV pulses are pseudo-Gaussian shaped with pulse length of 35-58 ns, FWHM 20-30 ns, and 12-14 ns for a 10-90\% rise in signal. The difference in IR shaped pulses especially in the front peak with varying pulse energy was found to be extremely important in machining $\mathrm{Si}$ in previous studies. Both the $65 \mathrm{~ns}$ and $200 \mathrm{~ns}$ IR pulses with varying pulse energies were selected for the machining comparison to examine the effects of IR shaped pulses. The $65 \mathrm{~ns}$ IR pulse is the closest to UV pulses in length ( $58 \mathrm{~ns}$ ), the $200 \mathrm{~ns}$ pulse represents the full feature of the IR laser shaped pulse; fast rise, high front peak and long energy tail, Fig. 1.

The lasers were focussed onto the surface of a polished single crystalline $\mathrm{Si}$ wafer, $650 \mu \mathrm{m}$ thick, with a <111> crystallographic orientation. Samples were examined using a Veeco NT3300 white light interferometer for profile, and a Zeiss 1640 cross beam scanning electron microscope to examine surface quality. All processing was done in ambient air, at standard temperature and pressure.

TABLE I

SYSTEM COMPARISON OF IR AND UV LASERS.

\begin{tabular}{|c|c|c|}
\hline Laser parameters & IR fibre laser & DPSS UV laser [31] \\
\hline Wavelength $\lambda$ & $1062 \pm 10 \mathrm{~nm}$ & $354.7 \mathrm{~nm}$ \\
\hline Max. Ave. Power $\mathrm{P}_{\max }$ & $20 \mathrm{~W}$ & $10 \mathrm{~W}$ at $60 \mathrm{kHz}$ \\
\hline Max. pulse energy $\mathrm{E}_{\mathrm{p}}$ & $0.55 \mathrm{~mJ} @ 35 \mathrm{kHz}$ & $0.17 \mathrm{~mJ} @ 60 \mathrm{kHz}$ \\
\hline Pulse Rep. Frequency & $\mathrm{CW}-500 \mathrm{kHz}$ & $1-300 \mathrm{kHz}$ \\
\hline Peak power & $<7 \mathrm{~kW}$ & $6.6 \mathrm{~kW}$ \\
\hline Waveforms & 25 preset & Pseudo Gaussian \\
\hline Beam diameter & $1 \mathrm{~mm}(\mathrm{x} 8$ expansion $)$ & $3.5 \mathrm{~mm} \pm 10 \%$ \\
\hline Pulse length & $20-220 \mathrm{~ns}$ & $<60 \mathrm{~ns}(<35 \mathrm{~ns}$ \\
\hline $\mathrm{M}^{2}$ & $<1.2$ & 1.3 \\
\hline Polarization & Random & Horizontal \\
\hline
\end{tabular}

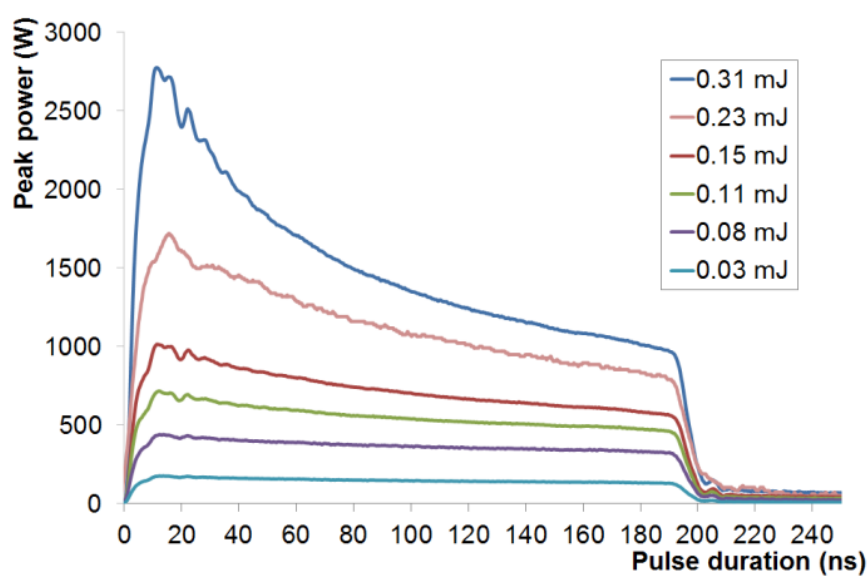

Fig. 2. Temporal pulse profiles of $200 \mathrm{~ns}$ IR laser pulses with varying pulse energy.

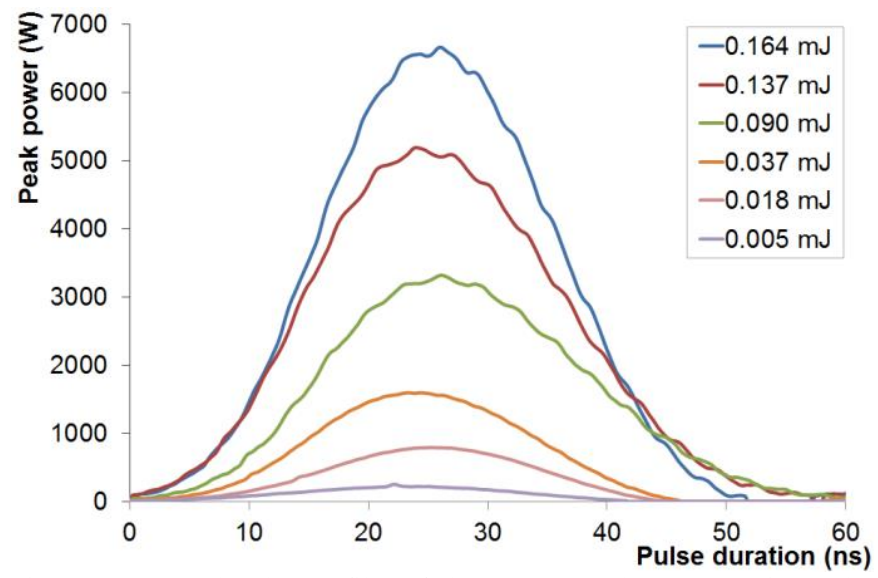

Fig. 3. Temporal pulse profiles of the DPSS UV laser at varying pulse energy. 


\section{MATERIAL PROPERTIES}

Silicon has a long $(200 \mu \mathrm{m})$ optical penetration depth at $\sim 1 \mu \mathrm{m}$ wavelength at room temperature, but this is not representative of the conditions during processing. At elevated temperatures, from $300 \mathrm{~K}$ to $1140 \mathrm{~K}$, the absorption coefficient has been shown to increase significantly from $\sim 50 \mathrm{~cm}^{-1}$ to over $10^{3} \mathrm{~cm}^{-1}$ at $1064 \mathrm{~nm}$, Fig. 4 [15]-[17]. The inset equation was later used in the theoretical calculations.

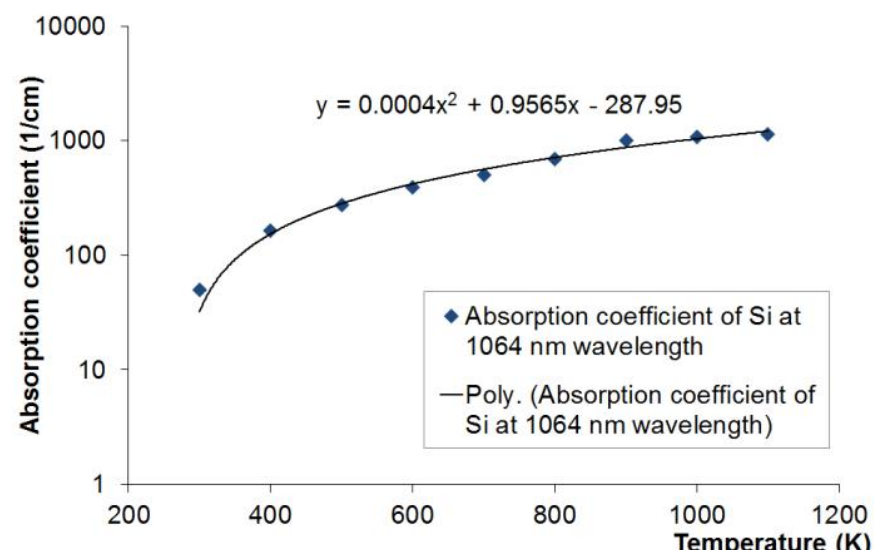

Fig. 4. Optical absorption coefficient of Si for $1064 \mathrm{~nm}$ as a function of temperature [15]-[17].

As an indirect bandgap material silicon allows only phononassisted transitions. The probability of such transitions depends on the phonon occupancy and is both low and temperature dependent. A temperature rise causes an increase in the phonon population, which then facilitates more phononelectron energy exchanges. Instead of oscillation and reradiation, the electrons are more likely to interact with the structure and further increase the absorption [18]. When silicon becomes molten, the absorption coefficient increases significantly as a result of many more valence electrons and adopts a metallic behaviour [19]. The optical penetration length of liquid Si decreases abruptly to $14.3 \mathrm{~nm}$ which allows the absorption of the laser radiation to take place very near to the surface [20], [21].

The optical and thermal properties of solid $\mathrm{Si}$ can be written as a function of temperature, TABLE II. The increase in absorption coefficient of $\mathrm{Si}$ makes laser heating of $\mathrm{Si}$ much more effective and the decrease in the thermal conductivity slows the energy loss due to heat conduction. Both changes are in favours of the laser machining of $\mathrm{Si}$ at $1062 \mathrm{~nm}$ wavelength. For the UV pulses, the optical absorption depth is as little as $10 \mathrm{~nm}$ for solid Si [22] and $7.7 \mathrm{~nm}$ for liquid Si [23], and remains constant across the temperature range for solid Si [24].

\section{THEORETICAL ANALYSIS}

With the dynamic material properties and IR laser's asymmetrical temporal pulse shape, the classic Fourier heat conduction equation cannot be applied directly to calculate the temperature distribution. Instead, the laser pulse was divided into many small equal time intervals. $t=t_{1}+t_{2}+t_{3} \ldots+t_{n}=n t_{n}$

where $n$ is the number of time intervals over time, $t$. A square pulse was considered within each time interval $\left(t_{n}=0.2 \mathrm{~ns}\right)$ and the material properties constant within each interval. The laser power density at each time interval, $I_{n}$, was calculated from the measured profiles.

TABLE II

SI OPTICAL AND THERMAL PROPERTIES AT 1062 NM AND 355 NM WAVELENGTH AS A FUNCTION OF TEMPERATURE ( $T<1683 \mathrm{~K}$ ).

\begin{tabular}{|c|c|c|c|}
\hline $\begin{array}{l}\text { Property (Solid } \\
\text { Si) }\end{array}$ & Values & Units & Refs. \\
\hline $\begin{array}{l}\text { Absorption } \\
\text { coefficient }\left(\alpha_{T}\right) \\
@ 1062 \mathrm{~nm} \\
\end{array}$ & $0.0004 T^{2}+0.9565 T-287.95$ & $\mathrm{~cm}^{-1}$ & $\begin{array}{l}{[15]-} \\
{[17]}\end{array}$ \\
\hline $\begin{array}{l}\text { Reflectivity }\left(R_{T}\right) \\
\text { @ } 1152 \mathrm{~nm}\end{array}$ & $31.2+2.2 \times 10^{-3} \mathrm{~T}$ & $\%$ & [15] \\
\hline $\begin{array}{l}\text { Absorption } \\
\text { coefficient }\left(\alpha_{T}\right) \\
\text { @ } 355 \mathrm{~nm}\end{array}$ & $10^{6}$ & $\mathrm{~cm}^{-1}$ & $\begin{array}{l}{[22],} \\
{[32],} \\
{[33]}\end{array}$ \\
\hline $\begin{array}{l}\text { Reflectivity }\left(R_{T}\right) \\
\text { @ } 355 \mathrm{~nm}\end{array}$ & 56 & $\%$ & [34] \\
\hline $\begin{array}{l}\text { Specific heat } \\
\left(C_{p_{T}}\right)\end{array}$ & $0.694 \times e^{2.375 \times 10^{-4} T}$ & $\mathrm{~J} / \mathrm{g} \cdot \mathrm{K}$ & \multirow{4}{*}{$\begin{array}{l}{[35],} \\
{[36]}\end{array}$} \\
\hline Density $(\rho)$ & 2.32 & $\mathrm{~g} / \mathrm{cm}^{3}$ & \\
\hline $\begin{array}{l}\text { Thermal } \\
\text { conductivity } \\
\left(\kappa_{T}\right)\end{array}$ & $\begin{array}{l}1521 T^{-1.226} \text { for } T \leq 1200 \mathrm{~K} \\
8.98 T^{-0.502} \text { for } 1200 \mathrm{~K}<T<T_{m}\end{array}$ & $\begin{array}{l}\mathrm{J} / \mathrm{cm} \cdot \mathrm{s} \cdot \\
\mathrm{K}\end{array}$ & \\
\hline $\begin{array}{l}\text { Thermal } \\
\text { diffusivity }\left(D_{T}\right)\end{array}$ & $D_{T}=\frac{\kappa_{T}}{\rho C_{p_{T}}}$ & $\mathrm{~cm}^{2} / \mathrm{s}$ & \\
\hline
\end{tabular}

Depending on the relationship between the thermal diffusion length $l_{\tau}=2 \sqrt{D \tau}$ ( $\tau$ is the pulse length) and the optical penetration length $l_{\alpha}=\frac{1}{\alpha}$, the expression for surface temperature $T_{S}(n)$ calculations in the current time internal $(n)$ at the centre of the irradiated zone can be derived based on equations from [25], [26].

In the case of a volume heating source $\left(l_{\alpha} \gg l_{\tau}\right)$,

$$
\begin{aligned}
T_{s}(n) & =\delta T+T_{s}(n-1) \\
& =\frac{\alpha_{(n-1)} I_{n}\left(1-R_{(n-1)}\right) t_{n}}{\rho C_{(n-1)}}+T_{s}(n-1) \\
& =\frac{t_{n}}{\rho} \sum_{i=1}^{i=n}\left(\frac{\alpha_{(i-1)} I_{i}\left(1-R_{(i-1)}\right)}{C_{(i-1)}}\right)+T_{0},
\end{aligned}
$$

similarly in the case of a surface heating source $\left(l_{\alpha} \ll l_{\tau}\right)$,

$$
\begin{aligned}
T_{s}(n) & =\delta T+T_{s}(n-1) \\
& =\frac{2 I_{n}\left(1-R_{(n-1)}\right) \sqrt{D_{(n-1)} t_{n}}}{\kappa_{(n-1)} \sqrt{\pi}}+T_{s}(n-1) \\
& =\frac{\sqrt{t_{n}}}{\sqrt{\pi}} \sum_{i=1}^{i=n}\left(\frac{2 I_{i}\left(1-R_{(i-1)}\right) \sqrt{D_{(i-1)}}}{\kappa_{(i-1)}}\right)+T_{0},
\end{aligned}
$$


$I_{0}=\sqrt{\frac{I_{1}^{2}+I_{2}^{2}+I_{3}^{2} \ldots+I_{n}^{2}}{n}}$

$I_{0}$ is the incident laser irradiance at the surface, and $T_{0}$ is the sample's initial temperature $(300 \mathrm{~K})$ across the target. $\alpha, R, C, \kappa$ and $D$ with the subscript are the temperature dependent absorption coefficient, surface reflectivity, specific heat, thermal conductivity and thermal diffusivity. When calculating the surface temperature in the current time interval $(n)$, the temperature dependent properties from the previous time interval $(n-1)$ were used.

When a $1062 \mathrm{~nm}$ wavelength laser irradiates $\mathrm{Si}$, the optical penetration depth $\left(l_{\alpha}=200 \mu \mathrm{m}\right)$ is much longer than the thermal diffusion length $\left(l_{\tau}=8.3 \mu \mathrm{m}\right)$, and the beam may be considered as a volume heating source. In this case, the forward heat conduction can be neglected.

Fig. 5 shows the surface temperature evolutions of $\mathrm{Si}$ irradiated by the IR laser with measured pulse profiles (Fig. 2) calculated using Equation 2.

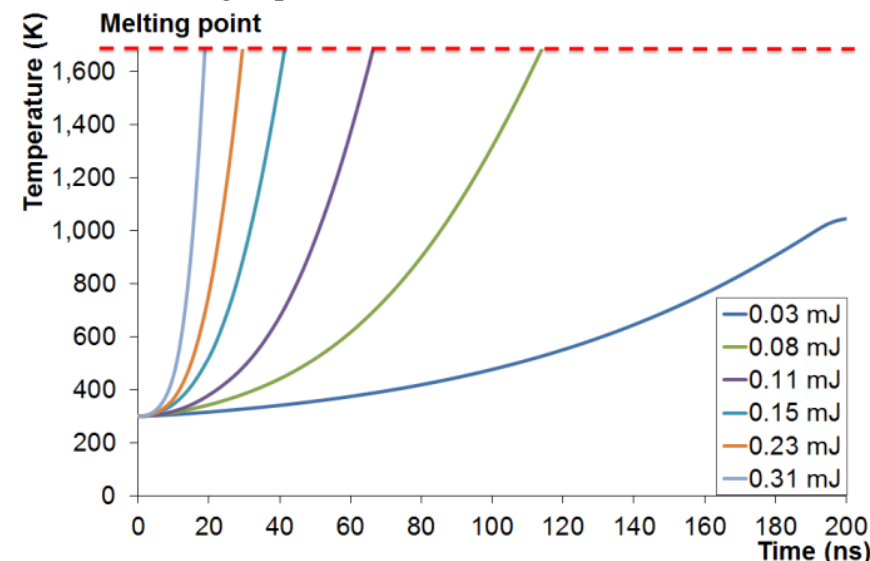

Fig. 5. Surface temperature distribution of Si irradiated by measured IR laser pulses in Fig. 2.

Modelling the measured IR pulses it can be seen that over the energy range the effect on the silicon ranges from just heating at $0.03 \mathrm{~mJ}$ to the generation of a melt pool within $20 \mathrm{~ns}$ with $0.31 \mathrm{~mJ}$, Fig. 5. After melting the optical penetration depth is reduced to $14.3 \mathrm{~nm} \mathrm{[20]} \mathrm{and} \mathrm{the}$ remaining pulse energy then acts as a surface heating source. This is much more effective and it is similar to the UV laser mechanism.

Fig. 6 shows the surface temperature evolutions of $\mathrm{Si}$ irradiated by the UV laser with measured pulse profiles (Fig. 3) calculated using Equation 3.

UV pulses with energies as low as $0.005 \mathrm{~mJ}$ were calculated to melt the Si surface within $10 \mathrm{~ns}$ of the laser pulse, the onset melting time decreased as the pulse energy was increased. The threshold pulse energy of the UV laser which results in $\mathrm{Si}$ machining is predicted to be ten times lower than the IR laser pulse.

\section{PERFORMANCE COMPARISON BETWEEN IR AND UV LASERS}

\section{A. Single Pulse Machined Depth and Efficiency}

The single pulse machined depth was plotted with respect to pulse energy for both lasers, Fig. 7. IR fibre laser machined depth data was obtained for two pulse lengths (65 ns and $200 \mathrm{~ns}$ ).

Comparing similar pulse lengths, the UV laser (58 ns) outperformed the IR laser (65 ns) with a lower machining threshold and higher machined depth in the same pulse energy range $(<0.16 \mathrm{~mJ})$.

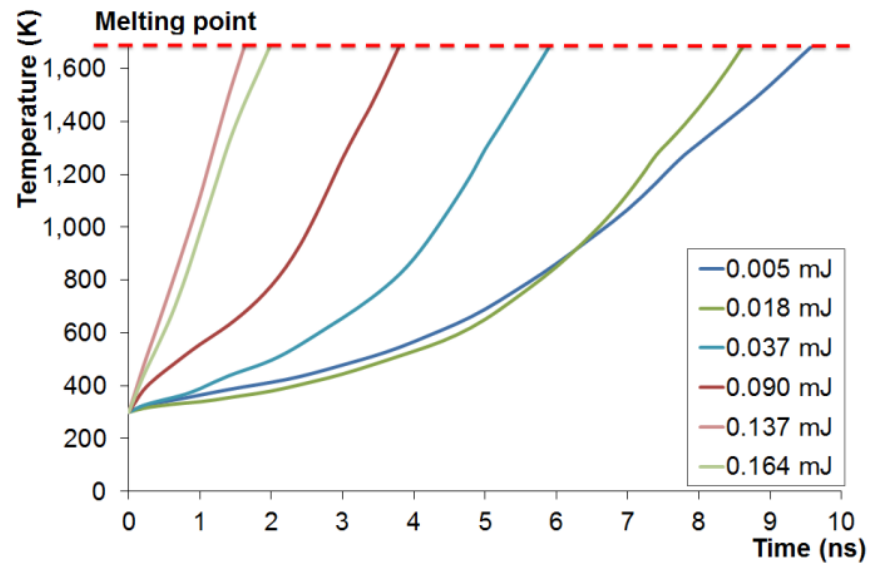

Fig. 6. Surface temperature distribution of Si irradiated by measured UV laser pulses in Fig. 3.

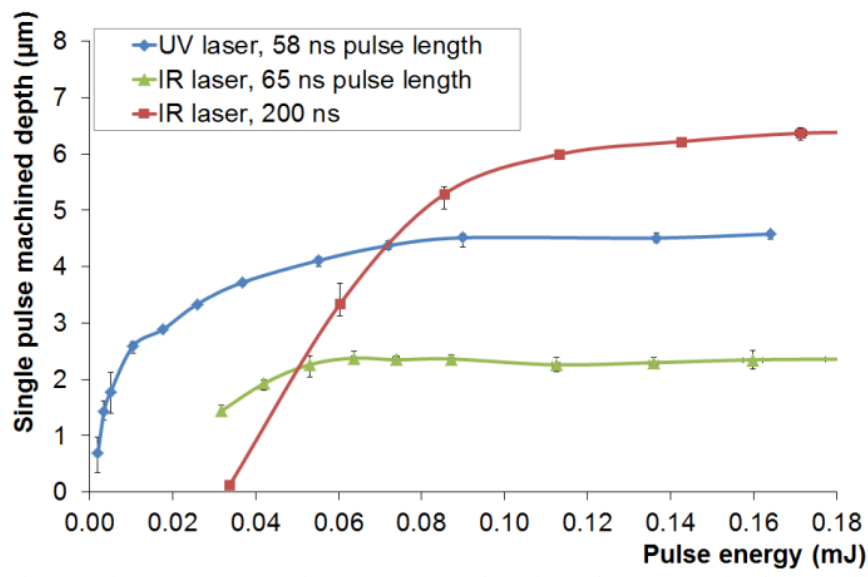

Fig. 7. Single pulse machined depth as a function of pulse energy for the IR fibre laser, 65 and $200 \mathrm{~ns}$ pulse lengths and UV laser, $58 \mathrm{~ns}$ pulse length.

When comparing longer IR pulses (200 ns) with UV, three incremental pulse energy regions were chosen based on the transitions between the different machining mechanisms induced by the IR fibre laser, low pulse energy ( $\leq 0.04 \mathrm{~mJ})$, intermediate pulse energy $(0.04-0.15 \mathrm{~mJ})$ and high pulse energy $(>0.15 \mathrm{~mJ})$.

1) Low pulse energy $(\leq 0.04 \mathrm{~mJ})$.

With IR pulses, there was little material removal due to poor energy coupling between the laser beam and Si. The surface temperature $T_{S c}$ at the centre of the irradiated zone for a volume source merely approaches the melting temperature of Si when pulse energies below $0.04 \mathrm{~mJ}$ were used, Fig. 5. With UV pulses the material removal started with a pulse 
energy as low as $0.005 \mathrm{~mJ}$; the $\mathrm{Si}$ surface was melted within $10 \mathrm{~ns}$ and molten layer removed with the remaining pulse energy. The removed depth increased rapidly to $\sim 3.8 \mu \mathrm{m}$ with increasing pulse energy.

2) Intermediate pulse energy $(0.04-0.15 \mathrm{~mJ})$.

With IR pulses, there was a significant increase of machined depth from zero to $\sim 6.2 \mu \mathrm{m}$, Fig. 7 . As the pulse energy, and peak power, increased the time taken to melt the surface of the material decreased. After melting there was also more energy in the remainder of the pulse which could then expel molten $\mathrm{Si}$ through vaporization and plasma pressure [27].

With UV pulses, there was only a slight increase in the machined depth, Fig. 7. Pulses above $0.015 \mathrm{~mJ}$ had power densities beyond the plasma shielding threshold of $0.2-0.3 \mathrm{GW} / \mathrm{cm}^{2}$ [28]. As a result the later part of laser pulse energy was shielded from the substrate by a dense plasma, and the machined holes were seen to widen with increased pulse energy.

3) High pulse energy (>0.15 $\mathrm{mJ})$.

For IR the machined depth curve begins to saturate around $0.15 \mathrm{~mJ}$ as a result of reaching the plasma shielding threshold $\left(0.2 \mathrm{GW} / \mathrm{cm}^{2}\right)$, Fig. 7. The machined depth for both lasers reached a plateau; $6.8 \mu \mathrm{m} /$ pulse was achieved with the IR laser compared with $4.5 \mu \mathrm{m} /$ pulse with the UV, both with pulse energies around $0.17 \mathrm{~mJ}$. The difference in machined depth per pulse is thought to correlate with the thermal diffusion length variation for the two wavelengths, $8.3 \mu \mathrm{m}$ for IR against $4.4 \mu \mathrm{m}$ with UV.

The single pulse machined depth was also plotted with respect to fluence for both lasers, Fig. 8, to include the spot size effects. The spot size of the IR laser is about $50 \%$ more than the UV laser, the IR fibre system offered high pulse energy to achieve the same fluence. The relationship between depth curves of both lasers is similar to Fig. 7. The UV laser achieved low damage threshold, high machined depth below $10 \mathrm{~J} / \mathrm{cm}^{2}$, while IR laser machined deeper features with $200 \mathrm{~ns}$ pulse above $10 \mathrm{~J} / \mathrm{cm}^{2}$.

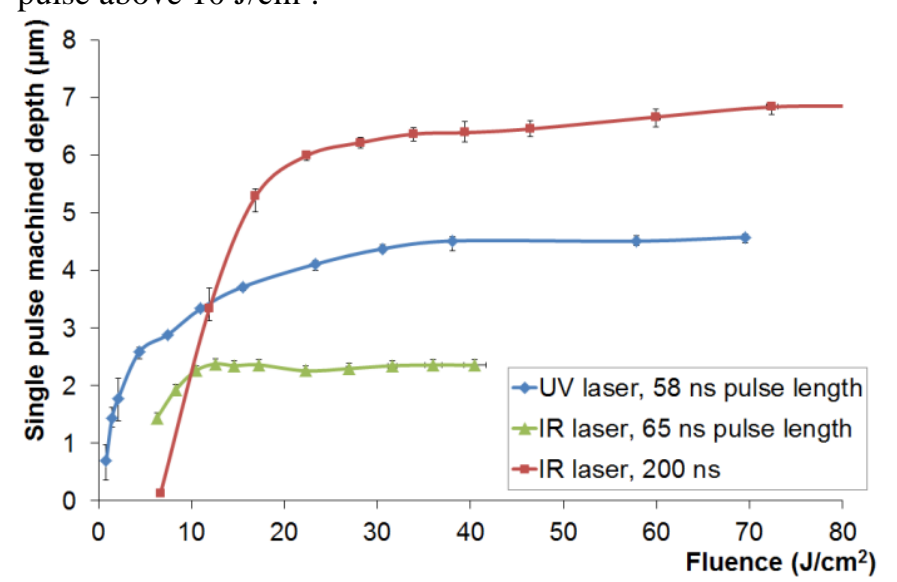

Fig. 8. Single pulse machined depth as a function of fluence for the IR laser, 65 and 200 ns pulse lengths and UV laser, 58 ns pulse length.

The single pulse machining energy efficiency is given for the UV laser and IR laser for pulse energies up to $0.17 \mathrm{~mJ}$,
Fig. 9, and for fluence up to $70 / \mathrm{cm}^{2}$, Fig. 10. Fig. 11The maximum machining energy efficiency over $400 \mu \mathrm{m} / \mathrm{mJ}$ is observed for the UV laser, six times higher than the IR $(\sim 60 \mu \mathrm{m} / \mathrm{mJ})$ occurring at a much lower pulse energy 0.003 $\mathrm{mJ}\left(1.5 \mathrm{~J} / \mathrm{cm}^{2}\right)$ for the UV compared with $0.085 \mathrm{~mJ}$ $\left(16.9 \mathrm{~J} / \mathrm{cm}^{2}\right)$ at IR, Fig. 9 and Fig. 10. With the high absorption coefficient on solid $\mathrm{Si}$, the theoretical melting threshold is calculated to be $0.0003 \mathrm{~mJ}\left(0.13 \mathrm{~J} / \mathrm{cm}^{2}\right)$. The smaller spot size which resulted in a higher fluence was also in favour for the UV laser. With pulse energies above $0.07 \mathrm{~mJ}$, the machining efficiency of the IR laser exceeded the UV laser. The is partly due to the fact that the UV laser reached a plasma shielding threshold with a much lower pulse energy of $0.015 \mathrm{~mJ}$, compared with $0.15 \mathrm{~mJ}$ for the IR laser. The efficiency curve of IR laser against fluence was always below the UV curve over the entire range, Fig. 10, which demonstrated the impact from UV laser's smaller spot size.

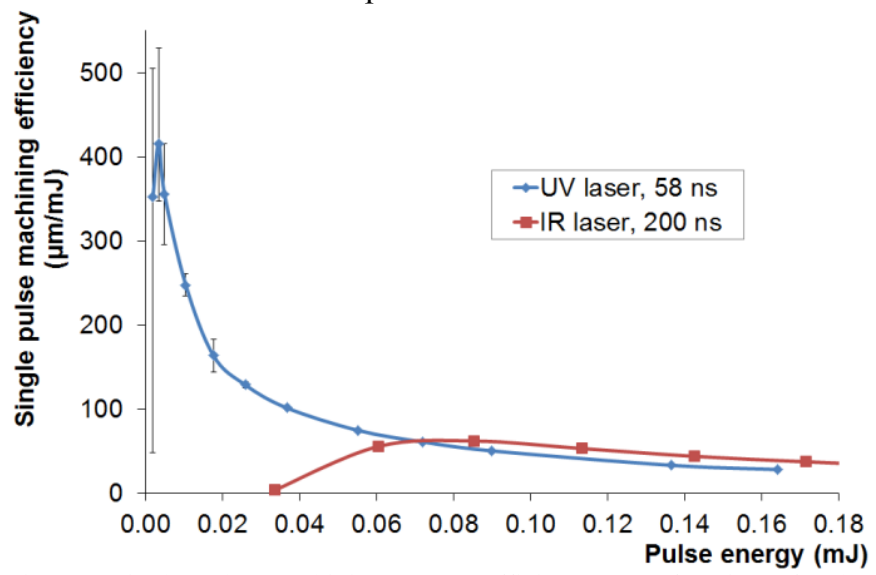

Fig. 9. Single pulse machining energy efficiency as a function of pulse energy for both the UV laser (58 ns) and IR fibre laser (200 ns).

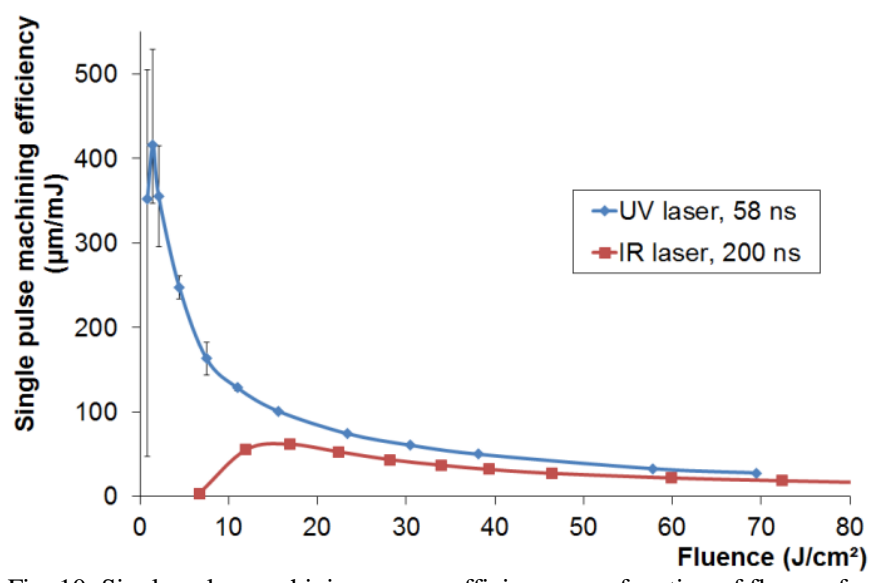

Fig. 10. Single pulse machining energy efficiency as a function of fluence for both the UV laser (58 ns) and IR fibre laser (200 ns).

\section{B. Single Pulse Machined Quality}

The machined quality of both lasers was compared in the same three pulse energy ranges, Fig. 11, and cross section examined with white light interferometer and plotted, Fig. 12.

1) Low pulse energy $(\leq 0.04 \mathrm{~mJ})$

The IR laser produced surface deformation of a few 


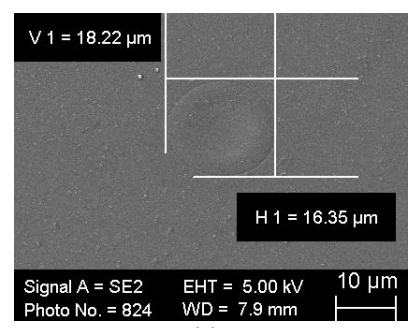

(a)

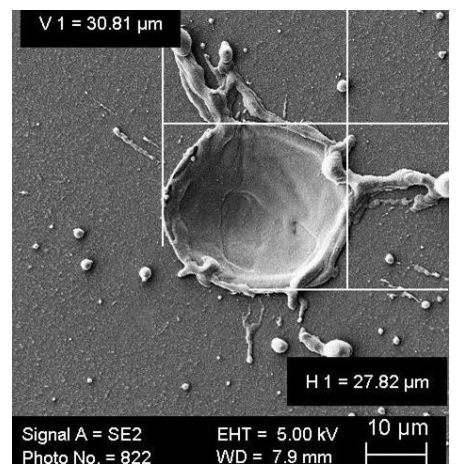

(b)

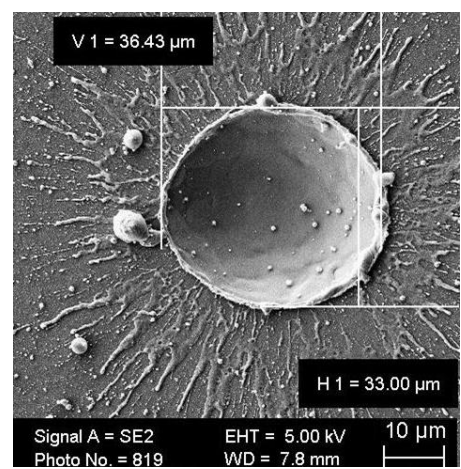

(c)

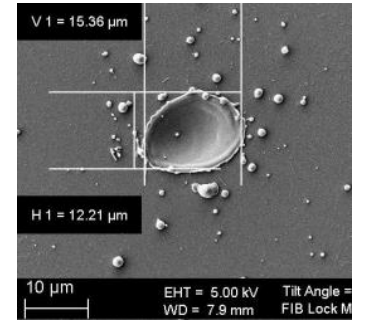

(d)

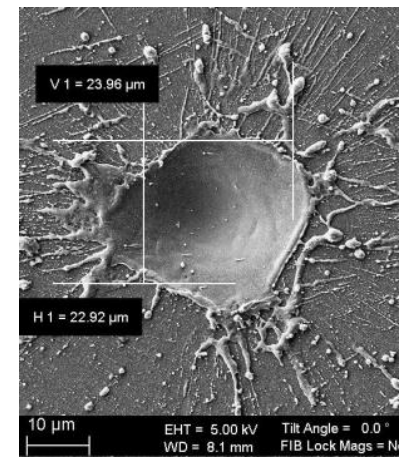

(e)

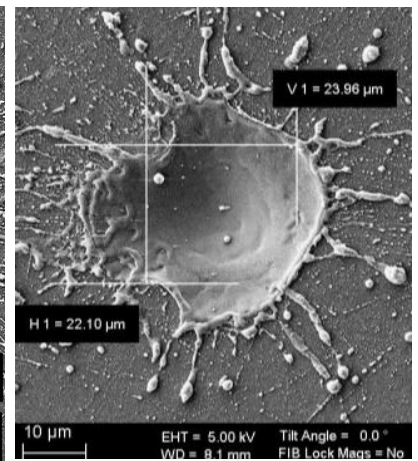

(f)

Fig. 11. Images of single pulse machined hole by the IR laser with the pulse energy of (a) $0.034 \mathrm{~mJ}$, (b) $0.085 \mathrm{~mJ}$ and (c) $0.171 \mathrm{~mJ}$ and by the UV laser with the pulse energy of (d) $0.005 \mathrm{~mJ}$, (e) $0.090 \mathrm{~mJ}$ and (f) $0.164 \mathrm{~mJ}$.

hundred nanometres with no material removal, Fig. 11(a) and Fig. 12(a). The UV laser produced the small holes $(<20 \mu \mathrm{m})$ with recast layer of $<1 \mu \mathrm{m}$ in height and $<5 \mu \mathrm{m}$ in width. The hole depth varied significantly, shown as large error bars in Fig. 9, and as such would not be suitable for industrial application. The non-circularity of the machined holes, Fig. 11(d) is due to the UV laser having a beam circularity specification of only $>85 \%$.

\section{2) Intermediate pulse energy $(0.04-0.15 \mathrm{~mJ})$}

Circularity of UV laser machined holes was seen to improve with increased pulse energy, Fig. 11(e), but the resolidified melt splash caused by the vapour pressure left an irregular hole shape. These resolidified layers are $\sim 1 \mu \mathrm{m}$ in height and extended over $\sim 10 \mu \mathrm{m}$ in width, Fig. 12(b). The IR laser machined holes show more defined circular edges, Fig. 11Fig. 11(b), covered with a recast layer of $<4 \mu \mathrm{m}$ in height and similarly extended over $\sim 10 \mu \mathrm{m}$ in width, Fig. 12(b). The thick recast layer was due to the low vaporisation pressure resulted from the low peak power of long IR pulses $(\sim 500 \mathrm{~W})$ and

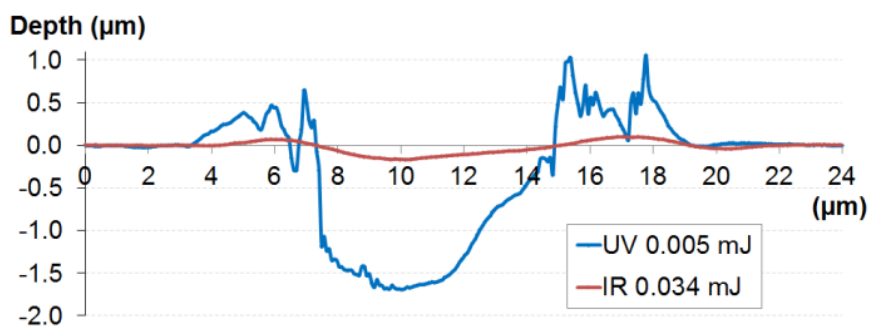

(a)

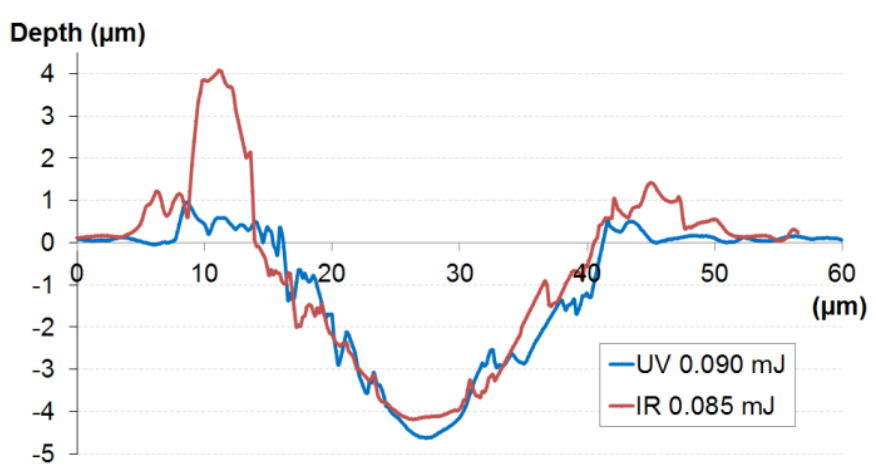

(b)

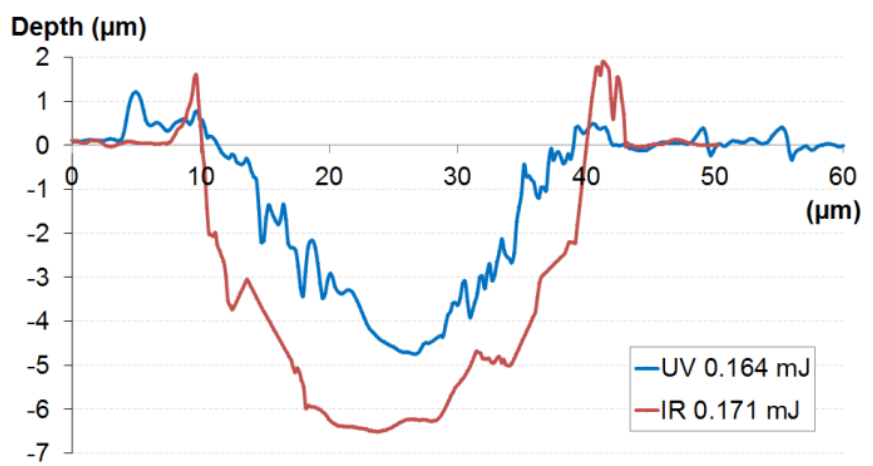

(c)

Fig. 12. Comparison of cross section surface profiles of single pulse machined hole by the IR and UV lasers with the (a) low pulse energy $(\leq 0.04 \mathrm{~mJ})$, (b) intermediate pulse energy $(0.04-0.15 \mathrm{~mJ})$, and (c) high pulse energy $(>0.15 \mathrm{~mJ})$.

large spot size $(25.4 \mu \mathrm{m})$ of IR system, compared with the UV pulses $(\sim 3000 \mathrm{~W}$ and $17 \mu \mathrm{m})$. Inside the craters, both laser machined featured show similar shape and roughness, Fig. 12(b).

3) High pulse energy (>0.15 $\mathrm{mJ})$.

For UV pulses, the machined features contain a large amount of thick resolidified melt splashes beyond the rim, Fig. 11(f). For IR pulses, the streaks of resolidified melt ejection are thinner and were uniformly distributed in the radial direction, Fig. 11(c). Holes produced by the IR laser also show a greater number of micron and sub-micron condensed particles which are formed later in time as the plasma expands and cools. The nanosecond energy enriched long tail of IR laser is thought to establish a long-persistence plasma similar to laser-induced breakdown spectroscopy (LIBS) applications [29]. The recast layer formed by the IR laser was slightly higher $(<2 \mu \mathrm{m}$ compared with $<1.2 \mu \mathrm{m}$ ), but much narrower than the UV laser ( $<3 \mu \mathrm{m}$ compared with $>10 \mu \mathrm{m})$, showing a more complete vaporisation. 


\section{CONCLUSION}

The single pulse machining of $\mathrm{Si}$ substrate with a pulse shapeable IR fibre laser and DPSS UV laser were compared in the same pulse energy and fluence range. The DPSS UV pulses are capable of machining small features, $<20 \mu \mathrm{m}$, with low pulse energies, $<0.04 \mathrm{~mJ}$, on $\mathrm{Si}$ but not with adequate pulse to pulse reliability. As the pulse energy is increased the long nanosecond IR fibre pulses were able to achieve equivalent or better performance with no micro cracks or micro cavities, usually present with the long wavelength laser processing. The surface temperature of $\mathrm{Si}$ substrate was calculated to increase much faster with the increasing front peak of IR pulses, which resulted in a much lower optical penetration length, based on the dynamic temperature dependent optical and thermal properties. Both lasers are able to control the machined depth and are suitable for thin film scribing applications, they can also control debris size through the induced plasma for the LIBS applications. High quality, more reliable, inexpensive single mode fibre laser sources offer more competitive manufacturing advantages for the material processing industry.

The study utilized the full feature of shaped fibre pulses during energy scale up instead of conventional way of using an optical attenuator for comparison with UV laser. We believe the unique character makes this IR fibre different from conventional IR laser sources and it is the reason that this IR laser could be a good substitution for Si micromachining.

The comparison in this paper was not based on the same spot size between the lasers, and fluence achieved was limited due to the scanner setup for high speed laser scribing and marking. The spot size was reported to change the average machined depth at constant fluence during percussion drilling [30]. This is an important aspect for the micromachining with nanosecond laser pulses. In addition, with the spot size variation the machining mechanism could enter more explosive material removal regime at high fluence with dramatic increase in machined depth. Further study will be done to explore this region and analyze the effects.

\section{REFERENCES}

T. Otani, L. Herbst, M. Heglin, S. V Govorkov, and A. O. Wiessner, "Microdrilling and micromachining with diode-pumped solid-state lasers," Appl. Phys. A Mater. Sci. Process., vol. 79, no. 4, pp. 13351339, 2004.

[2] K. Venkatakrishnan and B. Tan, "Interconnect microvia drilling with a radially polarized laser beam," J. Micromechanics Microengineering, vol. 16, no. 12, pp. 2603-2607, Dec. 2006.

[3] Y.-H. Lee and K.-J. Choi, "Analysis of silicon via hole drilling for wafer level chip stacking by UV laser," Int. J. Precis. Eng. Manuf., vol. 11, no. 4, pp. 501-507, Aug. 2010.

[4] H. Booth, "Laser Processing in Industrial Solar Module Manufacturing," J. Laser Micro/Nanoengineering, vol. 5, no. 3, pp 183-191, Dec. 2010.

[5] K. Kim, T. Kim, H. Park, S. Kim, and S. Cho, "UV laser direct texturing for high efficiency multicrystalline silicon solar cell," Appl. Surf. Sci., vol. 264, pp. 404-409, 2012.

[6] X. C. Wang, L. Y. L. Wu, Q. Shao, and H. Y. Zheng, "Laser micro structuring on a Si substrate for improving surface hydrophobicity," J. Micromechanics Microengineering, vol. 19, no. 8, p. 085025, Aug. 2009.
L. a. Dobrzański, a. Drygała, K. Gołombek, P. Panek, E. Bielańska, and P. Zięba, "Laser surface treatment of multicrystalline silicon for enhancing optical properties," J. Mater. Process. Technol., vol. 201, no. 1-3, pp. 291-296, May 2008.

D. a. Zuev, O. a. Novodvorsky, E. V. Khaydukov, O. D. Khramova, a. a. Lotin, L. S. Parshina, V. V. Rocheva, V. Y. Panchenko, V. V. Dvorkin, a. Y. Poroykov, G. G. Untila, a. B. Chebotareva, T. N. Kost, and M. a. Timofeyev, "Fabrication of black multicrystalline silicon surface by nanosecond laser ablation," Appl. Phys. B, vol. 105, no. 3, pp. 545-550, Jul. 2011.

H. Chen, Q. Liu, P. Yan, and M. Gong, "High-power $355 \mathrm{~nm}$ ultraviolet lasers operating at ultrahigh repetition rate," Laser Phys. Lett., vol. 10, no. 2, p. 25401, 2013.

W. O'Neill and K. Li, "High-Quality Micromachining of Silicon at 1064 nm Using a High-Brightness MOPA-Based 20-W Yb Fiber Laser," IEEE J. Sel. Top. Quantum Electron., vol. 15, no. 2, pp. 462-470, 2009.

S. T. Hendow and S. a Shakir, "Structuring materials with nanosecond laser pulses.," Opt. Express, vol. 18, no. 10, pp. 10188 99, May 2010.

H. Herfurth, R. Patwa, T. Lauterborn, S. Heinemann, and H. Pantsar, "Micromachining with tailored Nanosecond Pulses," in Proc. of SPIE, 2007, vol. 6796, p. 67961G-67961G-8.

K. Li and W. O'Neill, "Fibre laser microvia drilling and ablation of Si with tuneable pulse shapes," Int. J. Precis. Eng. Manuf., vol. 13, no. 5, pp. 641-648, May 2012.

Y. Zhou, B. Wu, S. Tao, A. Forsman, and Y. Gao, "Physical mechanism of silicon ablation with long nanosecond laser pulses at $1064 \mathrm{~nm}$ through time-resolved observation," Appl. Surf. Sci., vol. 257, no. 7, pp. 2886-2890, Jan. 2011.

5] G. E. Jellison and D. H. Lowndes, "Optical absorption coefficient of silicon at $1.152 \mu$ at elevated temperatures," Appl. Phys. Lett., vol. 41, no. 7, pp. 594-596, 1982.

H. A. Weakliem and D. Redfield, "Temperature dependence of the optical properties of silicon,” J. Appl. Phys., vol. 50(3), pp. 1491$1493,1979$.

G. G. Macfarlane, T. P. McLean, J. E. Quarrington, and V. Roberts, "Fine Structure in the Absorption-Edge Spectrum of Si," Phys. Rev., vol. 111 , no. 5, p. 1245, 1958.

W. M. Steen, Laser material processing, 2nd ed. London, UK: Springer, 1998.

9] K. Sokolowski-Tinten, J. Bialkowski, a. Cavalleri, D. von der Linde, a. Oparin, J. Meyer-ter-Vehn, and S. Anisimov, "Transient States of Matter during Short Pulse Laser Ablation," Phys. Rev. Lett., vol. 81, no. 1, pp. 224-227, Jul. 1998.

O. Muller, S. De Unamuno, B. Prevot, and P. Dhamelincourt, "Surface Morphology and Structural Modifications of Si Targets Submitted to Intense Pulsed Laser Irradiations," Phys. status solidi, vol. 158 , no. 2, pp. 385-396, 1996.

M. D. Shirk and P. A. Molian, "A review of ultrashort pulsed laser ablation of materials," J. Laser Appl., vol. 10, no. 1, pp. 18-28, 1998.

D. Bauerle, Laser Processing and Chemistry, 3rd ed. Berlin: Springer, 2000.

G. E. Jellison, D. H. Lowndes, D. N. Mashburn, and R. F. Wood, "Time-resolved reflectivity measurements on silicon and germanium using a pulsed excimer KrF laser heating beam," Phys. Rev. B, vol. 34, no. 4, p. 2407, 1986.

Jellison Jr. and F. A. Modine, "Optical absorption of silicon between 1.6 and $4.7 \mathrm{eV}$ at elevated temperatures," Appl. Phys. Lett., vol. 41, no. 2, pp. 180-182, 1982.

S. M. Metev and V. P. Veiko, Laser-Assisted Microtechnology, 2nd update. Berlin: Springer-Verlag, 1998.

H. W. B. D. Bäuerle F. Dausinger, K. Dörschel, A. Gebhardt,, M. G. M. Geiger H. Haferkamp, C. Hertzler, H. Hügel, O. Minet,, G. M. M. Möhrle W. O’Neill, W. Schulz, G. Sepold, H.J. Tiziani,, M. U. M. Totzeck H. Venghaus, F. Vollertsen, H. Welling,, and W. Wiesemann, Group VIII: Advanced Materials and Technologies Volume 1 Laser Physics and Applications Subvolume C: Laser Applications, vol. Subvolume . Germany: Springer-Verlag, 2004. L. Tunna, A. Kearns, W. O'Neill, and C. J. Sutcliffe,

"Micromachining of copper using Nd:YAG laser radiation at 1064, 532, and 355 nm wavelengths," Opt. Laser Technol., vol. 33, no. 3, pp. 135-143, 2001. 
R. E. Russo, "Laser Ablation,” Appl. Spectrosc., vol. 49, no. 9, p. 14A-28A, 1995.

[29] R. E. Russo, X. Mao, J. J. Gonzalez, and J. Yoo, "Femtosecond vs. Nanosecond Laser Pulse Duration for Laser Ablation Chemical Analysis," Spectroscopy, vol. 28, no. 1, pp. 24-39, 2013.

[30] F. Brandi, N. Burdet, R. Carzino, and A. Diaspro, "Very large spot size effect in nanosecond laser drilling efficiency of silicon.," Opt. Express, vol. 18, no. 22, pp. 23488-94, Oct. 2010.

[31] Coherent, "Coherent AVIA 355-10 Solid-State Q-Switched Ultraviolet Lasers Data Sheet." Coherent,

http://www.coherent.com/downloads/AVIA_355-10_DS_final.PDF, 2007.

[32] D. Bauerle, Laser Processing and Chemistry, 2nd ed. Berlin: Springer, 1996.

[33] E. D. Palik, Handbook of Optical Constants of Solids II. London: Academic Press, 1991, p. 1117.

[34] G. E. Jellison and F. A. Modine, "Optical functions of silicon between 1.7 and $4.7 \mathrm{eV}$ at elevated temperatures," Phys. Rev. B, vol. 27, no. 12, p. 7466, 1983.

[35] J. H. Yoo, S. H. Jeong, R. Greif, and R. E. Russo, "Explosive change in crater properties during high power nanosecond laser ablation of silicon," J. Appl. Phys., vol. 88, no. 3, pp. 1638-1649, 2000.

[36] S. De Unamuno and E. Fogarassy, "A thermal description of the melting of c- and a-silicon under pulsed excimer lasers," Appl. Surf. Sci., vol. 36, no. 1-4, pp. 1-11, 1989.

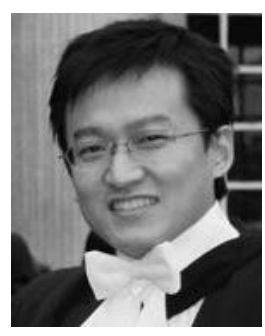

Kun Li was born in Ningxia, China in 1983. He received the B.Eng. degree in Electronics Engineering from the University of York, York, U.K., in 2006, and the M.Phil. degree in Industrial Systems in 2007 from University of Cambridge, Cambridge, U.K. He then received the Ph.D. degrees in laser micromachining from the Centre of Industrial Photonics, Department of Engineering, University of Cambridge, Cambridge, U.K. in 2012.

Since 2012, He has been working as a Research Associate in the Photonics \& Sensors Group, Electrical Engineering Division, Department of Engineering, University of Cambridge, U.K. His research interests include laser microprocessing, light matter interaction, liquid crystal lens design, fabrication and applications, and displays technology. He also gained industrial experience from SPI lasers, Southampton, UK and Ford Motor, Chongqing, China as a contractor and through summer internship.

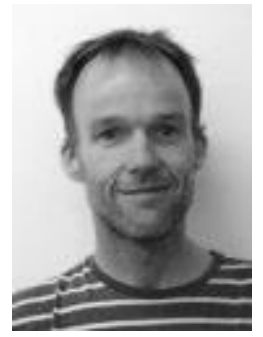

Martin Sparkes obtained a M.Eng in Mechanical Engineering from The University of Liverpool in 1991 and was subsequently employed as an R.A on Brite Euram project BE4046 looking into the control of laser beam properties for processing at distances over 40m. During this project studied part time for a $\mathrm{PhD}$ in high power laser beam diagnostics and control, awarded from Liverpool in 1996.
After the completion of studies he was employed as part of a team setting up the Lairdside Laser Engineering initiative aiming to promote and validate laser application within local industry. Returned back to Liverpool University as a Senior Research Fellow looking at the evolution of laser sheet metal cutting in the high-speed regime, and then moved to Cambridge in 2003 to be part of the Centre for Industrial Photonics.

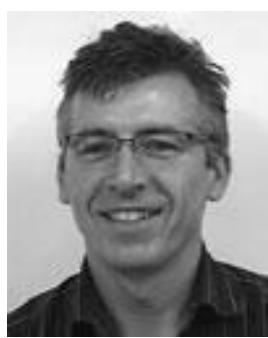

William O'Neill obtained a B.Sc in Applied Physics from the University of Essex in 1985 and an M.Sc in Laser Physics in 1986. On moving to the John Percy Group, Royal School of Mines, Imperial College, he studied the interaction phenomena of dualwavelength laser materials processing and obtained a PhD in 1990. He then moved to the University of Liverpool where he continued his research and supported Prof W M Steen in establishing one of the world's largest university based laser research groups.

$\mathrm{He}$ is a Professor of Laser Engineering within the Cambridge University Engineering Department. In 1990, he was awarded a five year Royal Society Research Fellowship to study the metal oxygen combustion process leading to the development of a high-efficiency deep-section laser cutting process at Liverpool University. In 1995, he was a Lecturer in the Department of Industrial Studies, where he established a laser-based manufacturing research group and developed new teaching materials for undergraduate manufacturing engineers. In 1998, he was awarded a five-year EPSRC to develop the laser-based microengineering production technologies. In 2001, he was awarded a £5 million Grant to establish an Innovative Manufacturing Research Center. In 2003, he moved to Cambridge University, Cambridge, U.K., where he is currently the Director of the Centre for Industrial Photonics.

Prof. O'Neill has written over 170 research publications and scientific papers on the subject of laser-matter interactions, optical engineering, laser based manufacturing technologies, and micro/nano fabrication techniques. He is a member of the international advisory panel of the National Laser Centre of South Africa, a Director of the Laser Institute of America, and advises industry on a number of laser based manufacturing technologies. 